\title{
Total synthesis of the novel tricyclic sesquiterpene sulcatine $\mathbf{G}$
}

\author{
Goverdhan Mehta* and Katukojvala Sreenivas
}

Department of Organic Chemistry, Indian Institute of Science, Bangalore, 560 012, India. E-mail: gm@orgchem.iisc.ernet.in

\section{Received (in Cambridge, UK) 18th April 2001, Accepted 13th August 2001 First published as an Advance Article on the web 4th September 2001}

A synthetic approach to the tricyclic sesquiterpene sulcatine G, 2, bearing a novel tricyclo[6.2.0.02,6]decane framework, from commercially available 1,5-cod and leading to the first total synthesis of the natural product is described.

The tricyclo[6.2.0.02,6]decane framework 1, constituted through the linear fusion of 4-5-5-membered carbocyclic rings, has been encountered only sporadically among the natural products. Among the very few known examples of terpenoid natural products based on this ring system are sulcatine $\mathrm{G}, \mathbf{2}$, from a Basidiomycetes fungi, ${ }^{1}$ kelsoene $\mathbf{3}$ from a tropical marine sponge Cymbastela hooperi ${ }^{2 a}$ and liverwort Ptychanthus stria$t_{u s^{2 b}}$ and poduran 4 from the springtail Podura aquatica. ${ }^{3}$

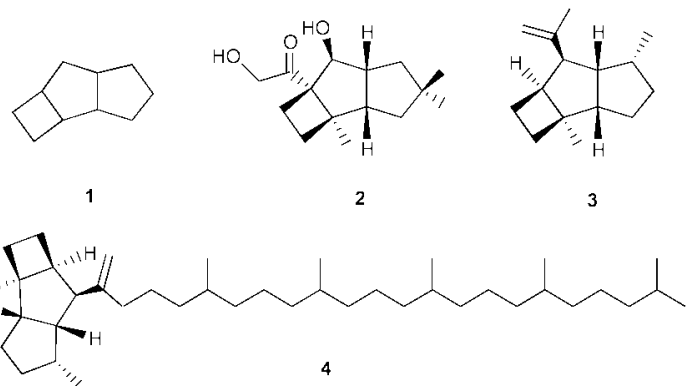

While these terpenes share the common cis, anti, cis-fused tricarbocyclic framework, they differ in the distribution of alkyl substitution and the level of functionalization. In an effort directed towards the synthesis of these novel natural products, we have recently accomplished the total synthesis of the hydrocarbon kelsoene $\mathbf{3}$ and established its absolute configuration. ${ }^{4,5}$ Continuing our efforts in the area, we have turned our attention towards the uniquely functionalized, 4-5-5-fused tricarbocyclic sesquiterpene sulcatine G, 2, which has also been shown to exhibit antifungal activity on Cladosporium cladosporioides and C. cucumerinum. ${ }^{1}$ Herein, we report the first total synthesis of sulcatine G, 2 which fully confirms the stereostructure of the natural product established earlier ${ }^{1}$ on the basis of NMR data.

Our synthetic approach to $\mathbf{2}$ was delineated through the retrosynthetic analysis indicated in Scheme 1. Accordingly, $\mathrm{C}_{15}$-tricyclic vinyl ketone $\mathbf{5}$ or an equivalent compound, embodying the entire skeleton of $\mathbf{2}$ and the two adjacent bridgehead quaternary cabon centres, emerged as the advanced precursor in which key functional group transformations could be effected en route to the natural product. The tricyclic ketone 5 in turn could be accessed from the diquinane $7^{6}$ via the intermediacy of the bicyclic enone-ester $\mathbf{6}$. The bicyclic ketone 7 has been prepared in a new sequence ${ }^{7}$ emanating from the commercially available cycloocta-1,5-diene $\mathbf{8}$ (1,5-cod), Scheme 2.

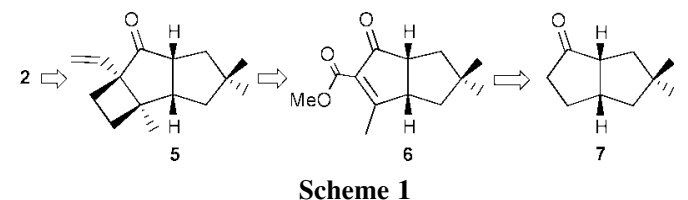

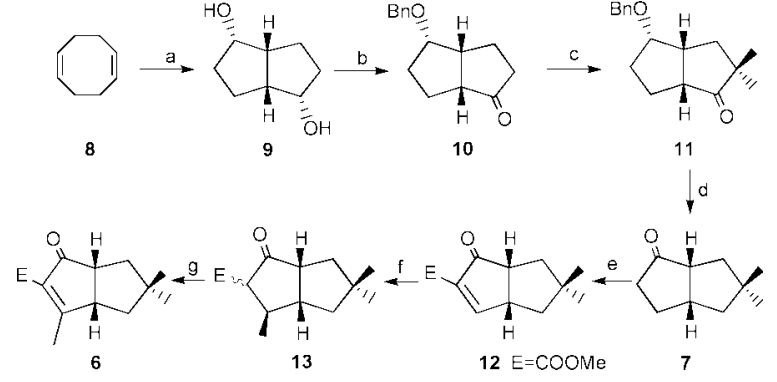

Scheme 2 Reagents: (a) i. $\mathrm{PdCl}_{2}, \mathrm{~Pb}(\mathrm{OAc})_{4}, \mathrm{AcOH}, 70 \%$, ii. $\mathrm{KOH}-\mathrm{MeOH}$, 95\%; (b) i. $\mathrm{NaH}, \mathrm{BnBr}, \mathrm{Bu}_{4} \mathrm{~N}^{+} \mathrm{I}^{-}$, THF, $85 \%$, ii. PCC, DCM, 92\%; (c) $\mathrm{K}^{+-} \mathrm{O}^{\mathrm{t} B u},{ }^{\mathrm{t}} \mathrm{BuOH}, \mathrm{MeI}, 90 \%$; (d) i. $\left(\mathrm{CH}_{2} \mathrm{SH}\right)_{2}$, toluene- $p$-sulfonic acid, benzene, $96 \%$, ii. Raney-Ni, EtOH, 90\%, iii. PCC, DCM, 90\%; (e) i. NaH, $(\mathrm{MeO})_{2} \mathrm{CO}$, benzene, ii. $\mathrm{NaH}, \mathrm{PhSeCl}$, THF, iii. $30 \% \mathrm{H}_{2} \mathrm{O}_{2}, \mathrm{DCM}, 66 \%$ (3 steps); (f) $\mathrm{MeMgI}, \mathrm{CuI}, \mathrm{Et}_{2} \mathrm{O}, 96 \%$; (g) i. $\mathrm{NaH}, \mathrm{PhSeCl}$, THF, ii. $30 \% \mathrm{H}_{2} \mathrm{O}_{2}$, DCM, $50 \%$.

$C_{2}$-Symmetric diquinane diol 9 was obtained from 1,5-cod in two steps involving $\mathrm{Pd}^{2+}$-mediated transannular cyclization and base hydrolysis as reported previously. ${ }^{8}$ Mono-protection of the hydroxy group and PCC oxidation in 9 led to 10. $\alpha$-gemDimethylation of $\mathbf{1 0}$ furnished $\mathbf{1 1}^{9}$ in which the carbonyl group was deoxygenated via thioketal formation and Raney-Ni desulfurization to furnish the debenzylated bicyclic alcohol in excellent yield which was further oxidized with PCC to give $7,7,9$ our main building-block for the synthesis of $\mathbf{2}$, Scheme 2 . A three step sequence from 7 involving $\alpha$-carbomethoxylation, phenylselenation-selenoxide elimination delivered the enoneester 12. ${ }^{9}$ 1,4-Addition of methylmagnesium iodide to $\mathbf{1 2}$ in the presence of $\mathrm{Cu}(\mathrm{I})$ installed the third methyl group and led to a diastereomeric mixture $13(80: 20)^{10}$ which was directly transformed to the enone-ester $6^{9}$ by repeating the phenylselenation-selenoxide elimination sequence, Scheme 2.

The diquinane enone-ester $6 \dagger$ had been crafted for the annulation of a four membered ring through the olefin-enone [ 2 $+2]$-photocycloaddition protocol. Irradiation of a mixture of 6 and $(E)-1,2$-dichloroethylene furnished the $[2+2]$-addition product $14^{9}$ as a mixture $(30: 70)$ of cis- and trans-1,2-dichloro isomers, respectively, in excellent yield. The two stereoisomers could be separated for characterization purposes but it was not necessary for the further transformations. The photocycloaddition to 6 proceeded exclusively from the exo-face of the diquinane moiety to generate the requisite cis, anti, cis ring junction stereochemistry in the natual product 2. DIBAL-H reduction of $\mathbf{1 4}$ followed by eliminative dehalogenation with sodium naphthalenide furnished an epimeric mixture of tricyclic cyclobutene diols $\mathbf{1 5 a} \mathbf{a}, \mathbf{b}(55: 45)$, Scheme $3 .{ }^{9}$ The major isomer 15a has the hydroxy group stereochemistry as in the natural product and is derived from the vicinal coupling $(J=$ $8.4 \mathrm{~Hz}$ ) between the trans disposed $\mathrm{H} 6-\mathrm{H} 7$ protons ( $c f . J=9$ $\mathrm{Hz}$ in sulcatine $\mathrm{G}, 2) .{ }^{1}$ In the minor isomer $\mathbf{1 5 b}$, coupling between cis disposed $\mathrm{H} 6-\mathrm{H} 7$ protons was $6.3 \mathrm{~Hz}$. Catalytic hydrogenation of $\mathbf{1 5 a}, \mathbf{b}$ readily furnished $\mathbf{1 6 a}, \mathbf{b} .{ }^{9}$ At this stage, the two hydroxy groups in the required epimer 16a needed to be differentiated. This was achieved through sequential protection of the primary and secondary hydroxy groups as the tbutyldimethylsilyl (TBDMS) ether and acetate groups, respectively, and 


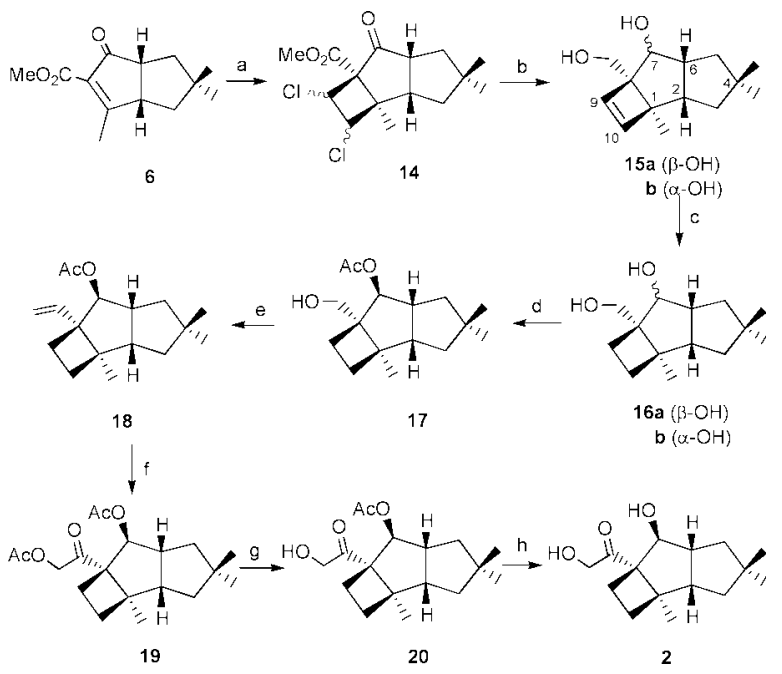

Scheme 3 Reagents: (a) (E)-1,2-dichloroethylene, $\mathrm{C}_{6} \mathrm{H}_{12}, h v$, pyrex, 94\%; (b) i. DIBAL-H, DCM, ii. sodium naphthalenide, DME, $(\mathbf{1 5 a}: \mathbf{1 5} \mathbf{b}=$ $55: 45$ ), $63 \%$ (2 steps); (c) $\mathrm{H}_{2}, 10 \% \mathrm{Pd} / \mathrm{C}$, EtOAc, $92 \%$; (d) i. 'BDMS-Cl, imidazole, DMAP, DCM, $91 \%$; ii. $\mathrm{Ac}_{2} \mathrm{O}$, DMAP, DCM, $100 \%$; iii. $2 \mathrm{~N}$ $\mathrm{H}_{2} \mathrm{SO}_{4}, \mathrm{MeOH}-\mathrm{H}_{2} \mathrm{O}, 87 \%$; (e) i. PCC, DCM, $90 \%$, ii. $\mathrm{MePPh}_{3} \mathrm{I}, \mathrm{KO}^{\mathrm{t}} \mathrm{Bu}$, THF, 92\%; (f) i. $\mathrm{OsO}_{4}, \mathrm{~N}$-methylmorpholine oxide $\mathrm{Me}_{2} \mathrm{CO}-\mathrm{H}_{2} \mathrm{O}, 85 \%$; ii. $\mathrm{Ac}_{2} \mathrm{O}$, DMAP, $100 \%$; iii. PCC, DCM, 75\%; (g) Sc(OTf) $3, \mathrm{MeOH}-\mathrm{H}_{2} \mathrm{O}$, $80 \%$; (h) $\mathrm{KOH}-\mathrm{MeOH}, 70 \%$.

further deprotection of the TBDMS group delivered the hydroxy-acetate 17.9 Oxidation of the primary hydroxy group in 17 with PCC to the aldehyde functionality and Wittig methylenation delivered 18, Scheme 3. Although 18 could be readily elaborated to the targeted advanced precursor $\mathbf{5}^{9}$ (Scheme 1) of sulcatine G, 2, tactical considerations at this stage required further processing through $\mathbf{1 8}$. Consequently, 18 was dihydroxylated and the primary hydroxy group in the resulting diol was selectively protected as the acetate. Further oxidation of the secondary hydroxy group delivered sulcatine $\mathrm{G}$ diacetate 19, spectroscopically identical with the diacetate reported from the natural product 2.1,9 Transformation of $\mathbf{1 9}$ to the natural product presented some problems but could be accomplished in two steps involving $\mathrm{Sc}(\mathrm{OTf})_{3}$ mediated hydrolysis of the $\alpha$ ketoacetoxy group ${ }^{11}$ to monoacetate $\mathbf{2 0}$ and further exposure to base furnished sulcatine G, 2, Scheme 3.9 Our synthetic 2 was found to be exactly identical with the natural product spectroscopically (IR, ${ }^{1} \mathrm{H}$ and ${ }^{13} \mathrm{C}$ NMR). ${ }^{1}$

In summary, we have outlined a stereocontrolled synthesis of the sesquiterpene sulcatine $G, 2$, from a readily available starting material (1,5-cod), which also unambiguously secures the stereostructure of the natural product.

We thank JNCASR for the financial support. One of us (K. S.) thanks UGC for the award of a research fellowship.

\section{Notes and references}

$\dagger$ The IUPAC name for diquinane is bicyclo[3.3.0]octane.

1 A. Arnone, G. Nasini and O. Vajna de Pava, J. Chem. Soc., Perkin Trans. 1, 1993, 2723.

2 (a) G. Konig and A. D. Wright, J. Org. Chem., 1997, 62, 3837; (b) K. Nabeta, K. Yamamoto, M. Hashimoto, H. Koshino, K. Funatsuki and K. Katoh, J. Chem. Soc., Chem. Commun., 1998, 1485.
3 S. Schulz, C. Messer and K. Dettner, Tetrahedron Lett., 1997, 38, 2077

4 (a) G. Mehta and K. Sreenivas, Synlett, 1999, 555; (b) G. Mehta and K. Sreenivas, Tetrahedron Lett., 1999, 40, 4877; (c) G. Mehta and K. Sreenivas, Tetrahedron Lett., 2001, 42, 2855.

5 Formation of the tricyclo[6.2.0.0 $\left.0^{2,6}\right]$ decane system has been recorded before, see: Y. Ohfune, H. Shirahama and T. Matsumoto, Tetrahedron Lett., 1975, 4377; G. Mehta and A. Srikrishna, Tetrahedron Lett., 1979 3187; A. J. H. Klunder, G. J. A. Ariaans, E. A. R. M. Van de Loop and B. Zwanenburg, Tetrahedron, 1986, 42, 1903. However, only one synthesis of a natural product based on this system has been recorded. $4 b, c$

6 For a recent review on the synthesis of polyquinane natural products, see: G. Mehta and A. Srikrishna, Chem. Rev., 1997, 97, 671.

7 For an earlier synthesis of diquinane 7, see: J. Cossy, D. Belotti and J.-P. Pete, Tetrahedron Lett., 1987, 28, 4547.

8 P. M. Henry, M. Davies, G. Ferguson, S. Philips and R. Restivo, Chem Commun., 1974, 112; G. Mehta and K. V. Rao, Indian J. Chem., Sect. B: Org. Chem. Incl. Med. Chem., 1991, 30B, 457.

9 All new compounds reported here were duly characterized on the basis of spectral (IR, ${ }^{1} \mathrm{H}$ and ${ }^{13} \mathrm{C} \mathrm{NMR}$ ) and analytical data. $J$ values are measured in Hz. Selected spectral data: 15a: IR (neat) $v_{\max } 3313,3047$, $1652 \mathrm{~cm}^{-1} ;{ }_{1}^{1} \mathrm{H} \mathrm{NMR}\left(300 \mathrm{MHz}, \mathrm{CDCl}_{3}\right): \delta 6.26(\mathrm{~d}, J 2.7,1 \mathrm{H}), 6.19(\mathrm{~d}$ $J 3.0,1 \mathrm{H}) 3.84(\mathrm{~d}, J 8.4,1 \mathrm{H}), 3.81($ br s, $2 \mathrm{H}), 2.48-2.23(\mathrm{~m}, 2 \mathrm{H}), 1.93$ $(\mathrm{m}, 2 \mathrm{H}), 1.76\left(\mathrm{dd}, J_{1} 13.5, J_{2} 8.1,1 \mathrm{H}\right), 1.60(\mathrm{~d}, J 13.5,1 \mathrm{H}), 1.40-1.30$ $(\mathrm{m}, 1 \mathrm{H}), 1.13(\mathrm{~s}, 3 \mathrm{H}), 1.06(\mathrm{~s}, 3 \mathrm{H}), 0.97(\mathrm{~s}, 3 \mathrm{H}) ;{ }^{13} \mathrm{C} \mathrm{NMR}(75.0 \mathrm{MHz}$ $\left.\mathrm{CDCl}_{3}\right): \delta 146.1,133.7,82.8,66.2,62.9,55.8,49.3,46.9,44.0,43.9$ 40.8, 31.5, 30.6, 16.1; EIMS (20 eV) $\mathrm{m} / \mathrm{z} 204\left(\mathrm{M}^{+}-18\right)$; 15b: IR (neat) $v_{\max } 3365,3032, \mathrm{~cm}^{-1} ;{ }^{1} \mathrm{H}$ NMR $\left(300 \mathrm{MHz}, \mathrm{CDCl}_{3}\right): \delta 6.10(\mathrm{~d}, J 3.0$ $1 \mathrm{H}), 5.92(\mathrm{~d}, J 3.0,1 \mathrm{H}), 3.97\left(\frac{1}{3} \mathrm{ABq}, J 11.7,1 \mathrm{H}\right), 3.92\left(\frac{1}{2} \mathrm{ABq}, J\right.$ 11.7, $1 \mathrm{H}), 3.97(\mathrm{~d}, J 6.3,1 \mathrm{H}), 2.85-2.75(\mathrm{~m}, 1 \mathrm{H}), 2.47-2.38(\mathrm{~m}, 1 \mathrm{H})$, $1.67-1.22$ (series of $\mathrm{m}, 4 \mathrm{H}), 1.18(\mathrm{~s}, 3 \mathrm{H}), 1.09(\mathrm{~s}, 3 \mathrm{H}), 1.00(\mathrm{~s}, 3 \mathrm{H}) ;{ }^{13} \mathrm{C}$ NMR (75.0 MHz, $\left.\mathrm{CDCl}_{3}\right): \delta 145.9,135.8,77.3,65.1,64.9,57.3,50.7$, 48.2, 43.8, 40.7, 38.4, 30.9, 29.5, 16.4; EIMS (20 eV) m/z $204\left(\mathrm{M}^{+}-\right.$ 18); 16a: IR (neat) $v_{\max } 3326 \mathrm{~cm}^{-1} ;{ }^{1} \mathrm{H}$ NMR $\left(300 \mathrm{MHz}, \mathrm{CDCl}_{3}\right): \delta$ $3.94(\mathrm{~d}, J 9.3,1 \mathrm{H}), 3.81\left(\frac{1}{2} \mathrm{ABq}, J 10.2,1 \mathrm{H}\right), 3.73\left(\frac{1}{2} \mathrm{ABq}, J 10.8,1 \mathrm{H}\right)$, 2.61-2.52 (m, 1H), 2.23-2.00 (series of $\mathrm{m}, 2 \mathrm{H}$ ), 1.90-1.52 (series of $\mathrm{m}$, $6 \mathrm{H}), 1.35\left(\mathrm{dd}, J_{1} 12.6, J_{2} 7.2,1 \mathrm{H}\right), 1.12(\mathrm{~s}, 3 \mathrm{H}), 1.00(\mathrm{~s}, 3 \mathrm{H}), 0.97(\mathrm{~s}$ $3 \mathrm{H}) ;{ }^{13} \mathrm{C} \mathrm{NMR}\left(75.0 \mathrm{MHz}, \mathrm{CDCl}_{3}\right): \delta 85.4,68.5,54.7,52.6,49.4,45.4$, 45.0, 44.0, 40.5, 31.8, 31.6, 30.6, 19.2, 17.0; EIMS (20 eV) $\mathrm{m} / z 206\left(\mathrm{M}^{+}\right.$ - 18); 16b: IR (neat) $v_{\max } 3366 \mathrm{~cm}^{-1} ;{ }^{1} \mathrm{H}$ NMR $\left(300 \mathrm{MHz}, \mathrm{CDCl}_{3}\right): \delta$ $3.93\left(\frac{1}{2} \mathrm{ABq}, J 11.4,1 \mathrm{H}\right), 3.85\left(\frac{1}{2} \mathrm{ABq}, J 11.4,1 \mathrm{H}\right), 3.82(\mathrm{~d}, J 5.7,1 \mathrm{H})$, $2.99-2.90(\mathrm{~m}, 1 \mathrm{H}), 2.42-2.32(\mathrm{~m}, 1 \mathrm{H}), 1.81-1.17$ (series of $\mathrm{m}, 8 \mathrm{H}), 1.12$ $(\mathrm{s}, 3 \mathrm{H}), 1.07(\mathrm{~s}, 3 \mathrm{H}), 1.01(\mathrm{~s}, 3 \mathrm{H}) ;{ }^{13} \mathrm{C} \mathrm{NMR}\left(75.0 \mathrm{MHz}, \mathrm{CDCl}_{3}\right): \delta 83.1$ 66.1, 58.0, 55.0, 48.1, 46.1, 44.1, 40.2, 38.7, 31.1, 30.4, 29.1, 23.1, 20.1 EIMS $(20 \mathrm{eV}) \mathrm{m} / z 206\left(\mathrm{M}^{+}-18\right) ; 18:$ IR (neat) $v_{\max } 3082,1738,1635$ $\mathrm{cm}^{-1} ;{ }^{1} \mathrm{H} \mathrm{NMR}\left(300 \mathrm{MHz}, \mathrm{CDCl}_{3}\right): \delta 5.88\left(\mathrm{AB} X, J_{1} 17.2, J_{2} 10.8,1 \mathrm{H}\right)$, $5.16(\mathrm{~d}, J 9.3,1 \mathrm{H}), 5.10\left(\mathrm{ABX}, J_{1} 10.8, J_{2} 1.5,1 \mathrm{H}\right), 4.98\left(A \mathrm{BX}, J_{1} 17.1\right.$, $\left.J_{2} 1.2,1 \mathrm{H}\right), 2.86-2.76(\mathrm{~m}, 1 \mathrm{H}), 2.33-2.23(\mathrm{~m}, 1 \mathrm{H}), 2.10-1.66$ (series of $\mathrm{m}, 6 \mathrm{H}), 2.01(\mathrm{~s}, 3 \mathrm{H}), 1.39\left(\mathrm{dd}, J_{1} 12.3, J_{2} 7,1 \mathrm{H}\right), 1.20-1.10(\mathrm{~m}, 1 \mathrm{H})$, 1.14 (s, 3H), 0.96 (s, 3H), 0.93 (s, 3H); ${ }^{13} \mathrm{C} \mathrm{NMR}\left(75.0 \mathrm{MHz}, \mathrm{CDCl}_{3}\right)$ : $\delta 170.9,141.9,113.5,86.2,55.3,54.5,49.0,48.5,44.8,43.8,40.5,31.7$, 31.5, 30.6, 21.2, 20.4, 17.1; EIMS $(20 \mathrm{eV}) \mathrm{m} / z 262\left(\mathbf{M}^{+}\right)$; 19: IR (neat) $v_{\max } 1736,1715 ;{ }^{1} \mathrm{H}$ NMR $\left(300 \mathrm{MHz}\right.$, acetone- $\left.\mathrm{d}_{6}\right): \delta 5.23(\mathrm{~d}, J 16.8$ $1 \mathrm{H}), 4.97(\mathrm{~d}, J 8.7,1 \mathrm{H}), 4.66(\mathrm{~d}, J 16.8,1 \mathrm{H}), 3.03-2.94(\mathrm{~m}, 1 \mathrm{H})$, $2.50-2.39(\mathrm{~m}, 1 \mathrm{H}), 2.34-2.25(\mathrm{~m}, 1 \mathrm{H}), 2.08(\mathrm{~s}, 3 \mathrm{H}), 2.02(\mathrm{~s}, 3 \mathrm{H})$, 2.01-1.78 (series of m, 4H), $1.65\left(\mathrm{dd}, J_{1} 13.8, J_{2} 2.4,1 \mathrm{H}\right), 1.53(\mathrm{t}, J 12.6$, $1 \mathrm{H}), 1.40-1.31(\mathrm{~m}, 1 \mathrm{H}), 1.15(\mathrm{~s}, 3 \mathrm{H}), 1.03(\mathrm{~s}, 3 \mathrm{H}), 0.99(\mathrm{~s}, 3 \mathrm{H}) ;{ }^{13} \mathrm{C}$ NMR $\left(75.0 \mathrm{MHz}\right.$, acetone- $\left.\mathrm{d}_{6}\right): \delta 203.8,171.5,170.3,88.2,68.3,63.0$, $55.4,53.9,50.3,45.5,44.0,41.0,31.8,31.3,30.8,21.0,20.6,20.4$, 14.5 .

10 The major isomer in $\mathbf{1 3}$ is expected to have $\beta$-methyl and $\alpha$ carbomethoxy groups in trans disposition through sequential addition and protonation from the convex face. However, the stereochemistry of 13 is inconsequential in the context of the further steps in the synthesis.

11 H. Kajiro, S. Mitamura, A. Mori and T. Hiyama, Tetrahedron Lett., 1999, 40, 1689. 